\title{
Cien años de paisajismo. \\ Desarrollo y alcances de la Arquitectura del Paisaje en Chile
}

\author{
One hundred years of landscape design. \\ Development and scope of landscape architecture in Chile
}

<Resumen>

El desarrollo de la arquitectura paisajista en Chile desde las primeras experiencias decimonónicas hasta el día de hoy, muestra una naciente maduración rumbo a temáticas ambientales, de sustentabilidad y sociales, al mismo tiempo de recuperar y reinterpretar tradiciones del pasado nacional.

$<$ Abstract $>$

The development of chilean landscape architecture since the xix century up to the present, shows both, a recent maturation towards environment. sustainability and social topics, whilst at the same time restoring and reinterpreting national traditions.

$<$ PALABRAS CLAVE >

ARQUITECTURA DEL PAISAJE / HISTORIA /

NATURALISMO / HUMANISMO / SUSTENTABILIDAD

<KEYWORDS>

LANDSCAPE ARCHITECTURE / HISTORY / NATURALISM / HUMANISM / SUSTAINABILITY

\section{Introducción}

Las palabras que siguen tienen como objetivo recorrer a grandes rasgos el desarrollo y los alcances de la arquitectura paisajista durante aproximadamente un siglo de historia nacional. Es opinión del autor, que tal lapso de tiempo es significativo para el paisajismo como disciplina -desde sus orígenes-, considerando la inminente celebración del Bicentenario de la República, y la conmemoración de un siglo de la realización del Parque Forestal en Santiago, primera obra moderna de paisajismo urbano en Chile.
En un estudio de este tipo es inevitable reconocer un pasado, como aquel período en que es posible leer algunas obras y labores significativas siguiendo una lógica lineal y cronográfica, y una actualidad más compleja y multifacética cuyo inicio se puede considerar en los años '90, paralelamente al cambio de paradigma que la misma historia de la arquitectura hace coincidir con la realización del Pabellón de Chile en la Exposición de Sevilla del '92, en que es más difícil encontrar un hilo conductor y en donde las mismas preocupaciones de la tradición vuelven a surgir reinterpretadas.

\footnotetext{
Arquitecto Roma TRE (revalida Universidad de Chile), Arquitecto del Paisaje PUC. Ha trabajado en proyectos de espacios públicos con Marta Viveros y en obras en tierra cruda con Marcelo Cortés. Actualmente se dedica a proyectos independientes y trabaja en el taller de arquitectura de la SECPLA de la Municipalidad de Vitacura, encargado de proyectos como los nuevos parques al borde de Mapocho y colaborador en la jecución Bicentenario. Fue coprofesor en los Talleres de la Escuela de Arquitectura de la Universidad de Talca hasta el 2008 y es corresponsal para Chile de // Giornale dell' Architettura, periódico italiano de arquitectura.
} 
Imagen 1. Parque Forestal, vegetación. George Dubois (fuente: Fulvio Rossetti).

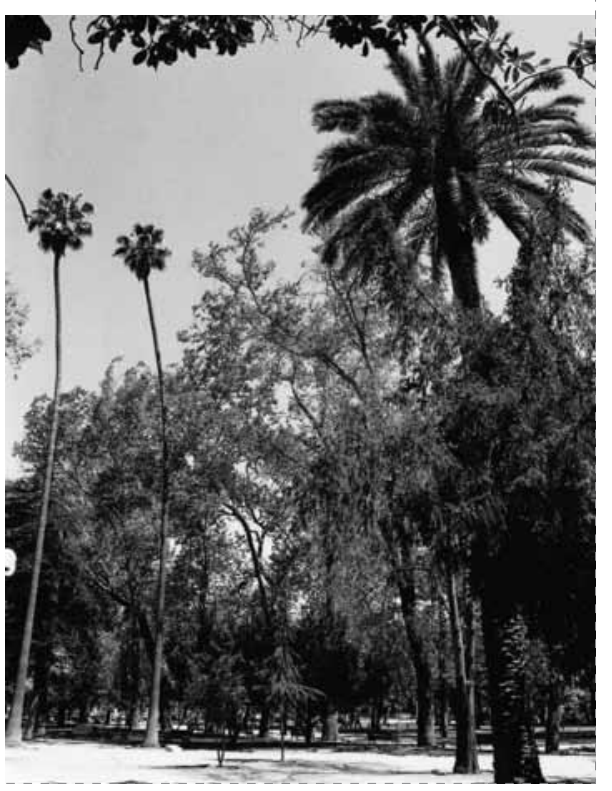

Desde la importación de modelos foráneos a la búsqueda de un lenguaje adecuado

Es común entre los paisajistas desprestigiar la obra anterior a la llegada de Óscar Prager por el poco uso que se hacía de la vegetación autóctona y el mayor prestigio asociado a la plantación de especies provenientes de Europa. Sin embargo más allá de juicios éticos sobre lo autóctono o lo exótico, el modelo de urbanismo a la francesa que inspiró Vicuña Mackenna a fines del siglo xıx dejó una huella importante que merece ser recordada no tanto por cuestiones de estilo sino que por la pragmaticidad de entender verde y espacio público como elementos estratégicos para la planificación.

Entre las obras de Vicuña Mackenna se encuentran: un anillo para Santiago, un camino de circunvalación que, además de separar lo urbano de la «barbarie», conectara las áreas verdes de la ciudad como la Quinta Normal de Agricultura; el cerro Santa Lucía (remodelado por su voluntad) y el Parque Cousiño, donación de la homónima familia aristocrática. El Parque Forestal (Imagen 1) se realizó en ocasión del primer Centenario, materializando la visión del intendente algunas décadas después de que éste había propuesto la canalización del Mapocho. En la transformación de Santiago esta obra se fundamentaba con el mejoramiento higiénico de la capital y, al mismo tiempo, el importante

Imagen 2. Parque Providencia, vista áerea. Óscar Prager (fuente: Archivo Museo Historico Nacional).
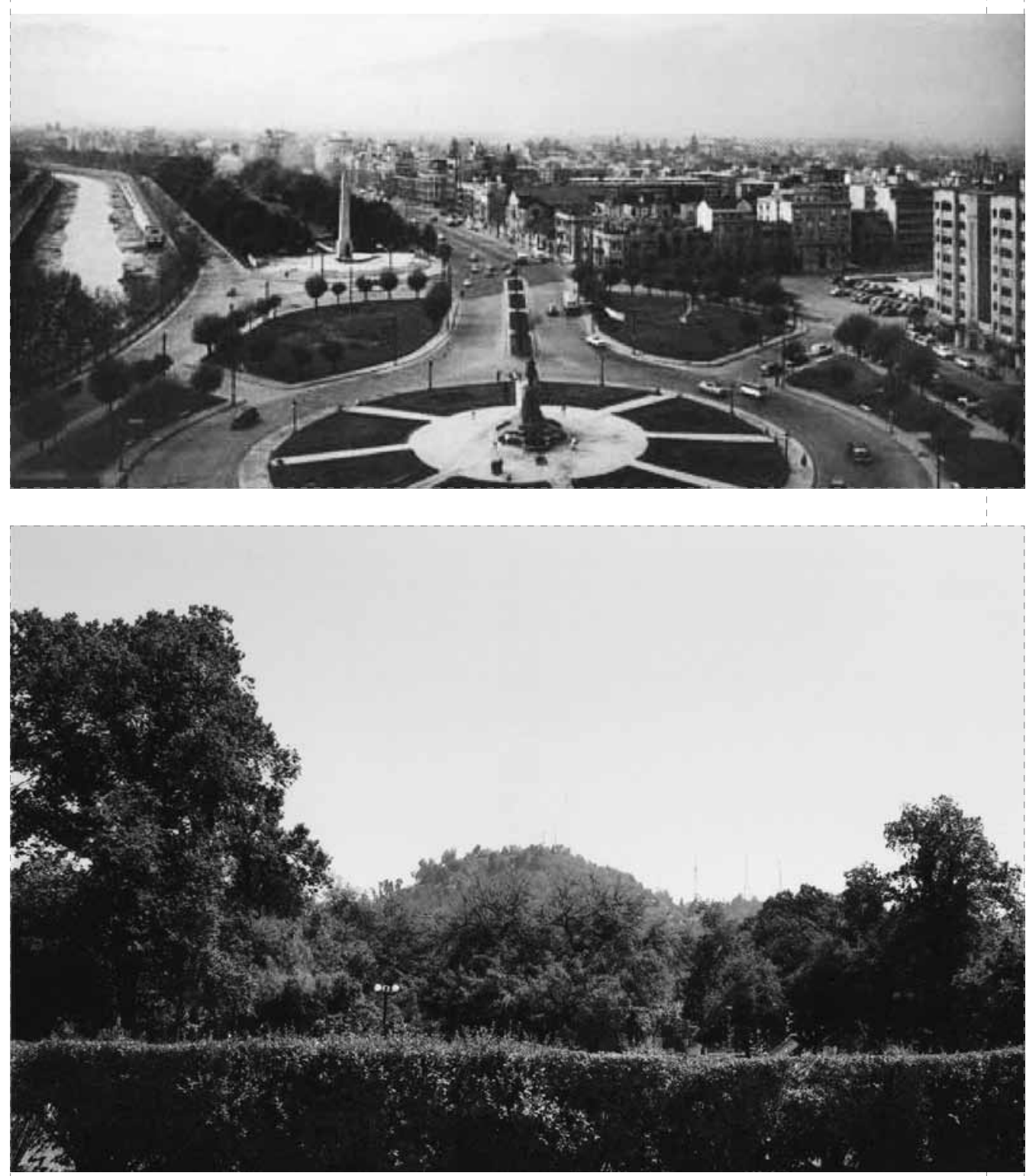

Imagen 3. Parque Providencia, masas arbóreas y Cerro San Cristóbal. Óscar Prager (fuente: Fulvio Rossetti).

negocio inmobiliario que podría generar un parque de borde río, en las áreas que antes eran inundables. Con el pasar de los años el parque adquirió una mayor envergadura; al funcionar como conexión entre dos estaciones de ferrocarriles (Estación Mapocho al poniente y Estación Pirque al oriente), cerraba la circunvalación ferroviaria de la ciudad, pasando a ser un moderno umbral infraestructural, al mismo tiempo que un importante acceso formal de ésta.
Óscar Prager, paisajista austríaco, difundió con su obra nuevos -para Chile- principios de diseño naturalista, propios de la tradición anglosajona. En este sentido el Parque Providencia de Santiago (1931), continuación del Parque Forestal hacia el oriente (Imagen 2), sigue siendo una referencia importante por su diseño abocado al descubrimiento de la naturaleza mediante el uso riguroso de las masas vegetales (Imagen 3), según principios visuales como los decritos e ilustrados en Sketches and hints on landscape gardening (Humphry Repton, 1752-1818). 
Las primeras obras de Carlos Martner se insertan en el contexto de los años '60 y del clima ideológico-reformista de esa época, en que el mundo artístico buscaba una nueva modernidad, madura, como mediación cultural entre lo propio y las vanguardias internacionales; las piscinas Tupahue y Antilén (Imágenes 4 y 5) (inauguradas respectivamente en 1966 y 1976) son obras maestras emblemáticas de esta manera de operar, donde se aplican principios visuales análogos al funcionalismo, sin por esto renunciar a un trazado fuertemente orgánico y construyendo un paisaje abstracto a la vez de integrar en él elementos del universo cultural precolombino.

Bajo una mirada alternativa la experiencias de Ameréida y la Ciudad Abierta de Ritoque también enfrentan desde los '70 el tema de la búsqueda de lo propio. De hecho no es casual el título del manifesto de esta escuela de pensamiento, al nacer como Silogismo entre Aeneida y América, al declarar la voluntad de un acto de fundación para la cultura del continente. En una suerte de proceso fenomenológico propuesto como manera de llegar a una arquitectura original, el paisaje natural se presenta como forma subyacente y a menudo fuente de inspiración ya sea para obras edificadas o espacios al aire libre. Una manera en todos sentidos poética -los actos poéticos de la escuela preceden cualquier obra- (Imágenes 6 y 7 ) de leer el entorno y "presentarlo» es la que se puede ver en obras como la Casa de los Nombres (Imagen 8), el Palacio del Alba y del Ocaso (Imagen 7), el Cementerio (Imagen 9) o las esculturas de Claudio Girola (Imagen 10).

De los '90 al día de hoy: dialogando con

\section{las tradiciones}

Si ya desde las primeras intervenciones en el territorio santiaguino para el primer Centenario de la República, se generó un desarrollo del pensamiento paisajista que a través de la labor de George Dubois (Parque Forestal), Óscar Prager, Carlos Martner y la Ciudad Abierta de Ritoque, dio origen a un patrimonio en que territorialidad, naturalismo, abstracción, memoria histórico-cultural y fenomenología se han ido interrelacionando. Al día de hoy la disciplina sigue desarrollándose sobre estos mismos temas, integrando una cantidad siempre mayor de variables ambientales, ecológicas, sociales, políticas, urbanísticas y económicas, las que se traducen en temas de diseño y amplían el espectro de posibilidades de acción de la disciplina. Frente
Imagen 4. Piscna Tupahue. Carlos Martner (fuente: Guy Wenborne)
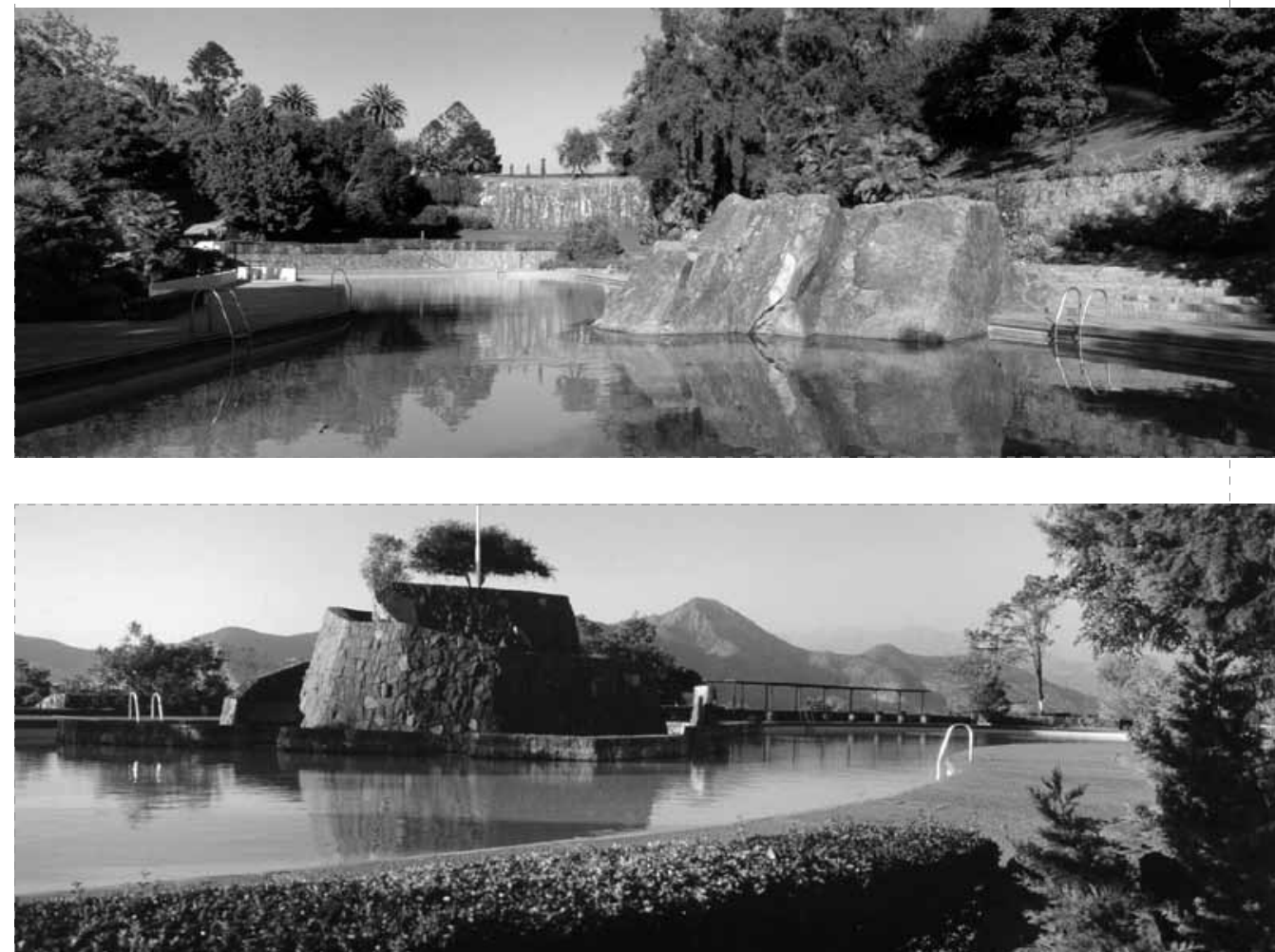

Imagen 5. Piscina Antilén. Carlos Martner (fuente: Guy Wenborne)

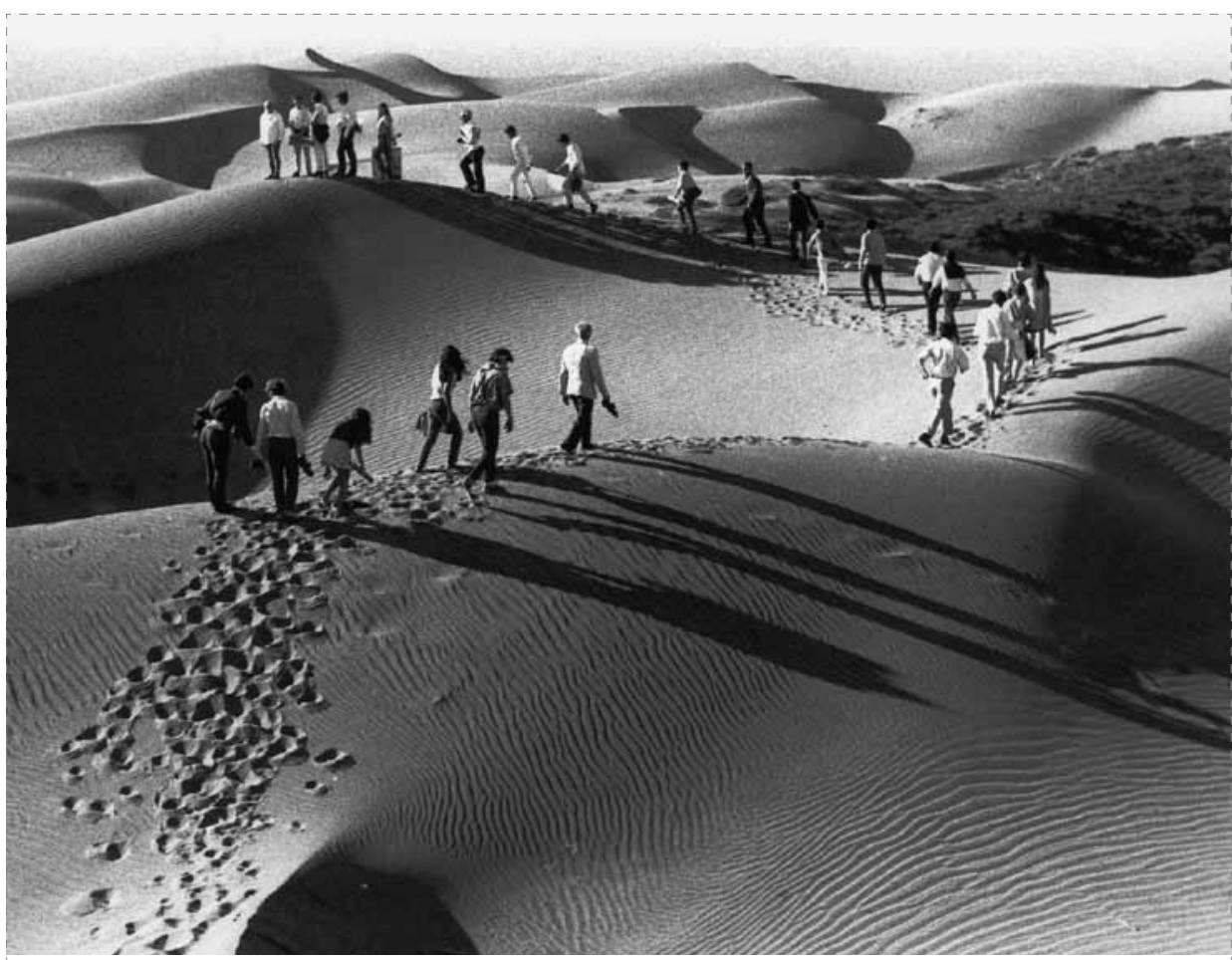

Imagen 6. Ciudad abierta, acto poético de apertura de los terrenos

(fuente: Archivo Histórico "José Vial Armstrong», Universidad Católica de Valparaíso). 
Imagen 7. Ciudad abierta, acto poético en el Palacio del Alba y del Ocaso (fuente: Archivo Histórico «José Vial Armstrong», Universidad Católica de Valparaísol.
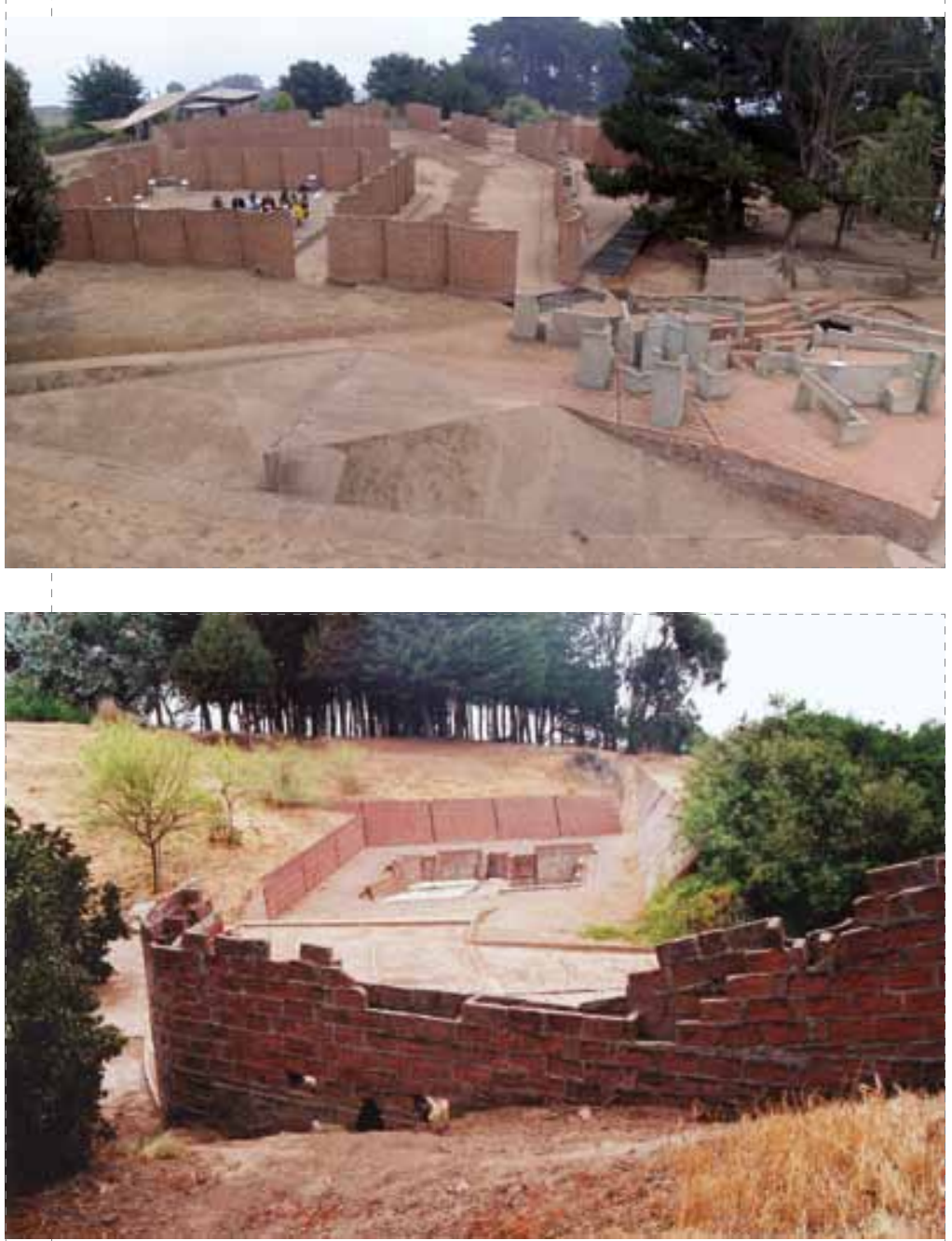

Imagen 9. Ciudad abierta, Cementerio

(fuente: Fulvio Rossetti).
Imagen 8. Ciudad abierta, Casa de los Nombres (fuente: Archivo Histórico "José Vial Armstrong», Universidad Católica de Valparaísol.
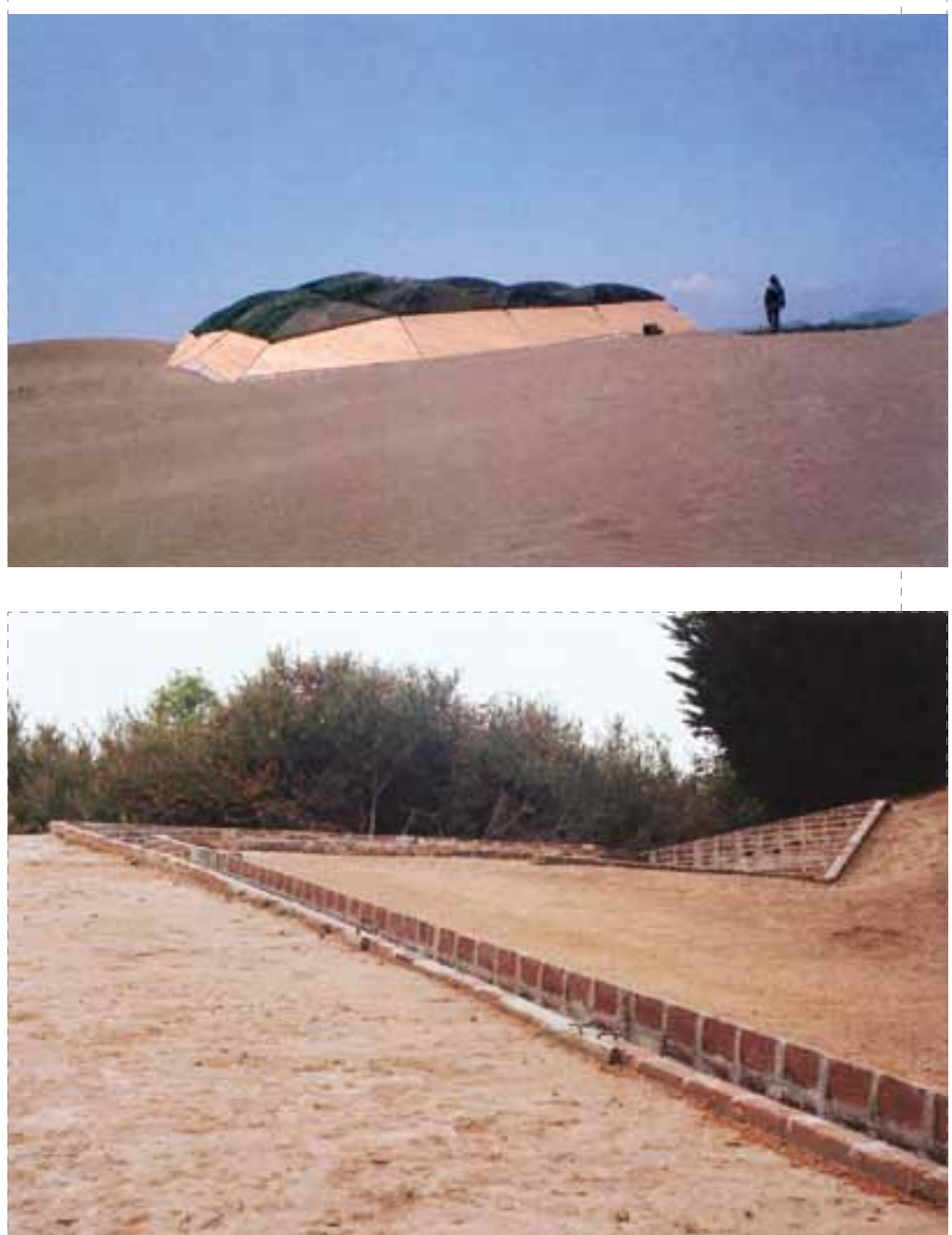

Imagen 10. Ciudad abierta, escultura El Pozo. Claudio Girola

(fuente: Fulvio Rossetti). a esta realidad, bastante compleja, más que hablar de la obra de algún arquitecto, parece oportuno evidenciar algunas recurrencias en la manera de enfrentar el proyecto de paisaje.

La actitud naturalista: se trata de una manera «contemplativa» de entender la naturaleza y la intervención en el territorio, que ve su origen en el modelo anglosajón, importado en Chile por Óscar Prager en los años '20 y que seguramente hasta hoy ha mantenido la mayor difusión tanto en la enseñanza académica como en el ámbito profesional, especialmente por concepto de la iniciativa privada. En una manera tradicional de entender el proyecto, seguramente Juan Grimm (Imagen 11) ha sido el arquitecto que con más vigor ha generado un gran patrimonio de parques y jardines particulares. Sin embargo, no obstante al día de hoy en lo general se aluda a la actitud naturalista como al diseño de jardines, algunos proyectos recientes como Paisajismo para la Reserva (Teodoro Fernández) (Imagen 12), el Parque Quebrada Los Chanchos (Cecilia Rencoret y Carla Rüttimann) (Imagen 13) Corredores Ecológicos Viña Emiliana (Teodoro Fernández) (Imagen 14) y el Parque Botánico El Chagual (Cristina Felsenhardt, Hans Muhr, Juana Zunino) (Imagen 15), muestran renovadas preocupaciones hacia temas medioambientales y de sustentabilidad, donde la reconstitución de dinámicas y paisajes naturales se profundiza también a un nivel de conocimiento científico. En los primeros dos casos la ingeniería hidráulica permitió la construcción de un parque inundable, a la vez de buscar un mejor manejo de la erosión del suelo y de los aluviones a valles; en el tercero un estudio ecológico fue aplicado para el mejoramiento de la viticultura y la construcción de un paisaje productivo, mientras que en el último la investigación sobre las relaciones entre altitud y especies vegetales equivalentes en distintas áreas geográficas, precedió la construcción de un paisaje expositivo.

En una actitud humanista la composición adquiere una connotación netamente cultural y la materia natural se carga de valores simbólicos, relacionados al imaginario colectivo. Se trata por lo demás de intervenciones públicas en áreas urbanas, en la cuales, si por un lado se conciben las áreas verdes y los espacios públicos como lugares estratégicos para la planificación urbana, por otro se hacen cargo de una exigencia cultural de sentido de pertenencia, como vehículo 


\section{$\begin{array}{llll}N & 0 & 1 & 9\end{array}$}

de arquitectura

Imagen 11. Jardín Los Vilos, Juan Grimm

(fuente: Juan Grimm).

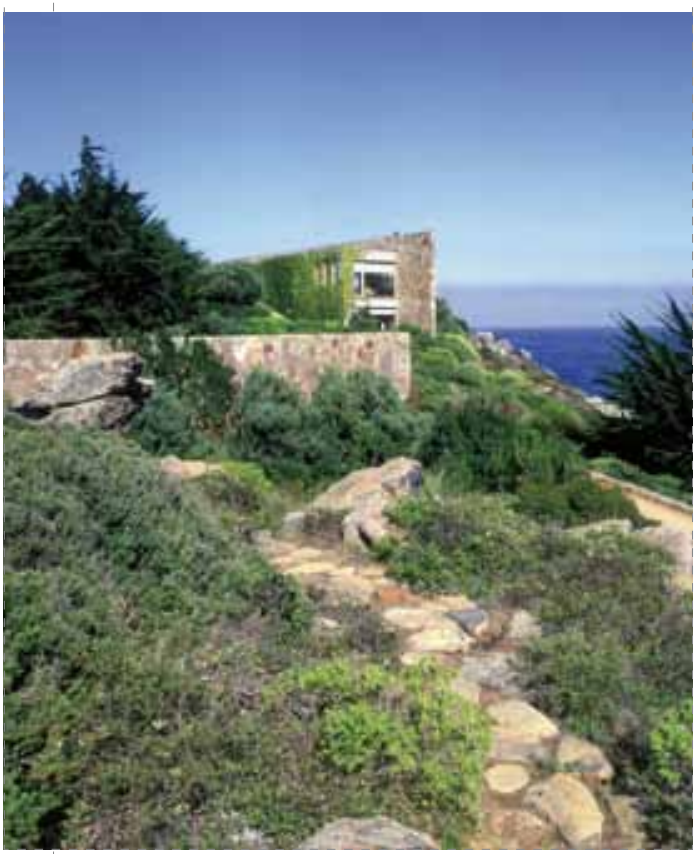

Imagen 12. Paisajismo para

la Reserva, tratamiento del cauce. Teodoro

Fernández (fuente: T. Fernández).

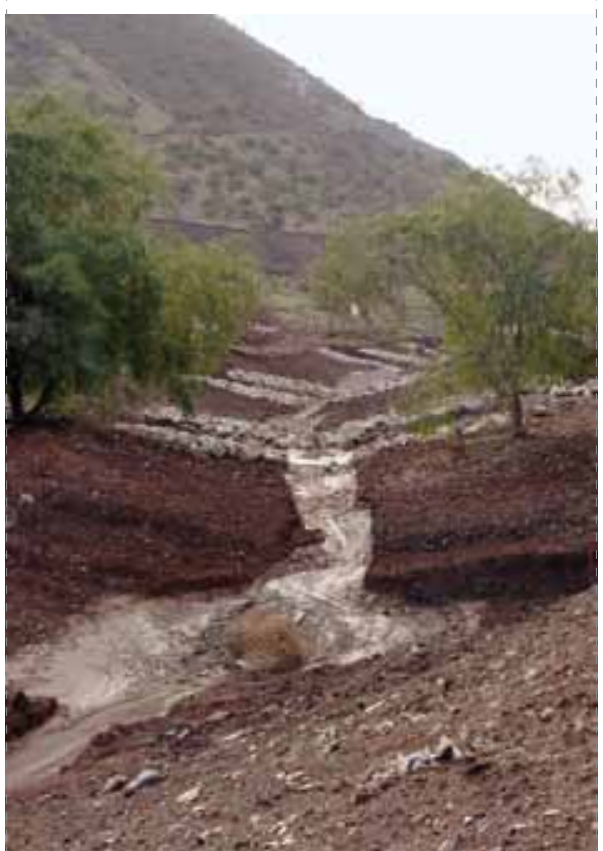

Imagen 13. Parque Quebrada Los Chanchos, Plaza redonda. Cecilia Rencore y Carla Rüttimann (fuente: RyR)

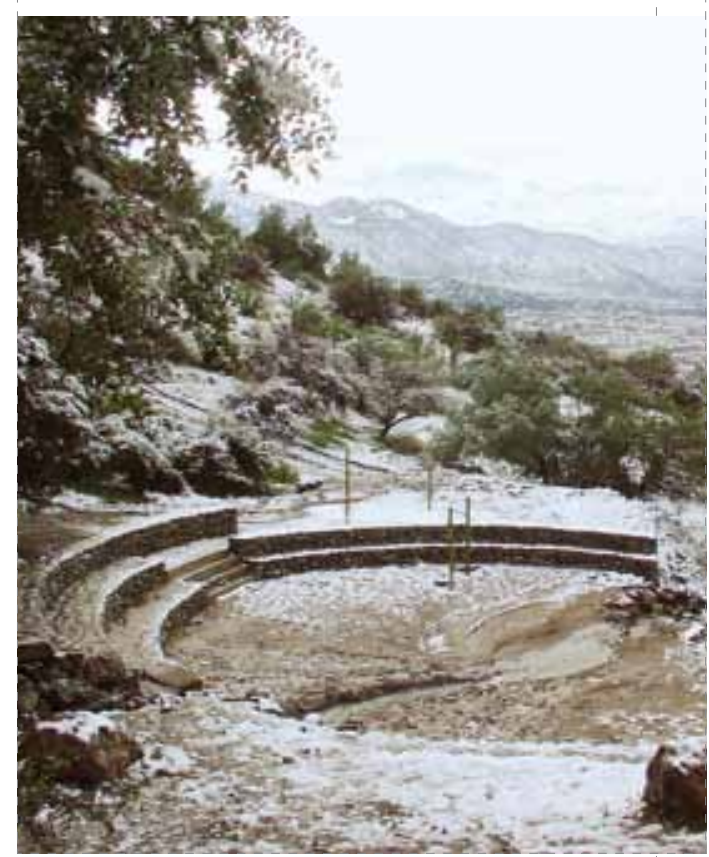

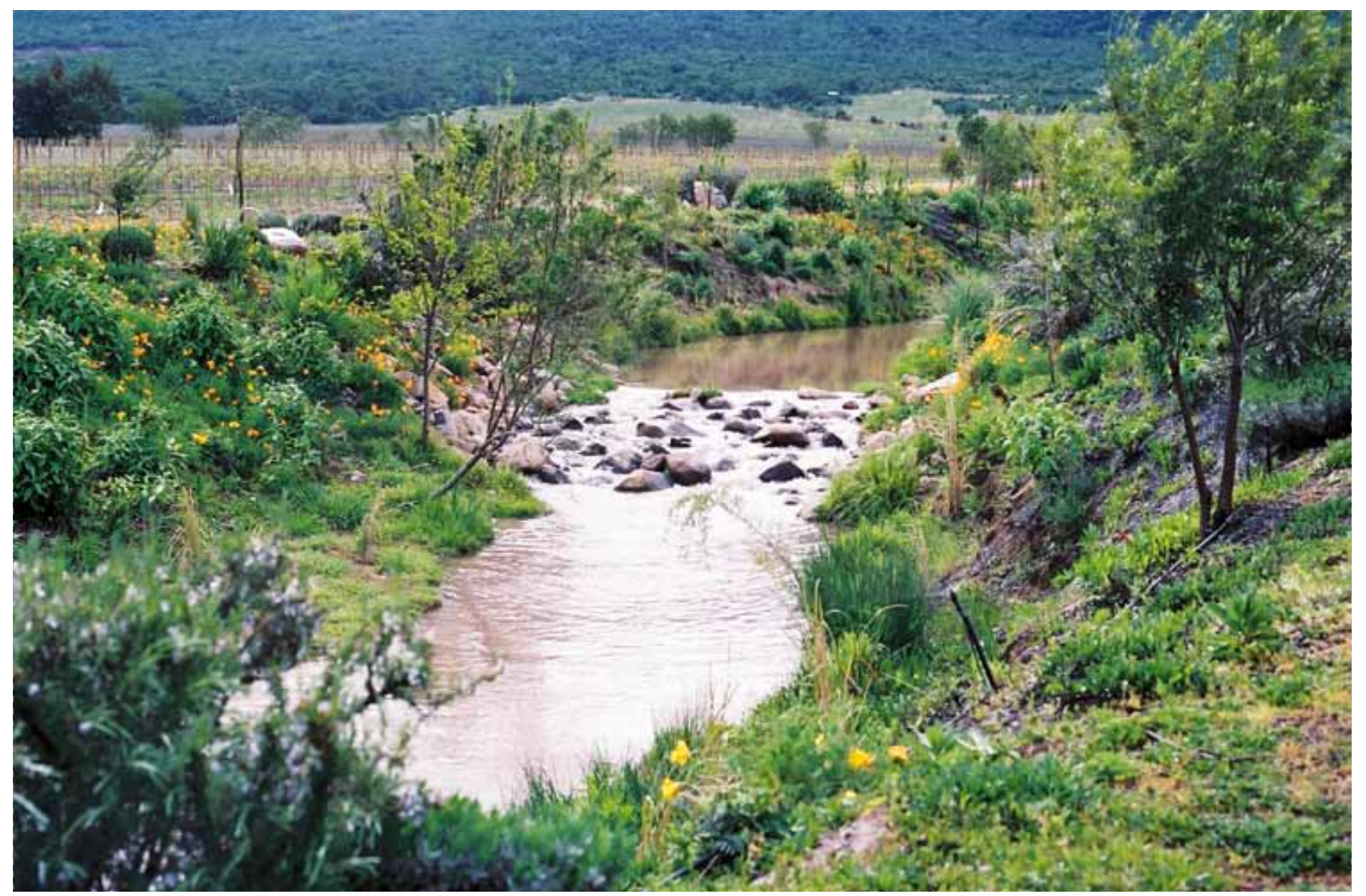

Imagen 14. Corredores Ecológicos Viña Emiliana. Teodoro Fernández (fuente: Teodoro Fernández). 
Imagen 15. Parque Botánico El Chagual. Felsenhardt, Muhr y Zunino (fuente: Felsenhardt, Muhr, Zunino).

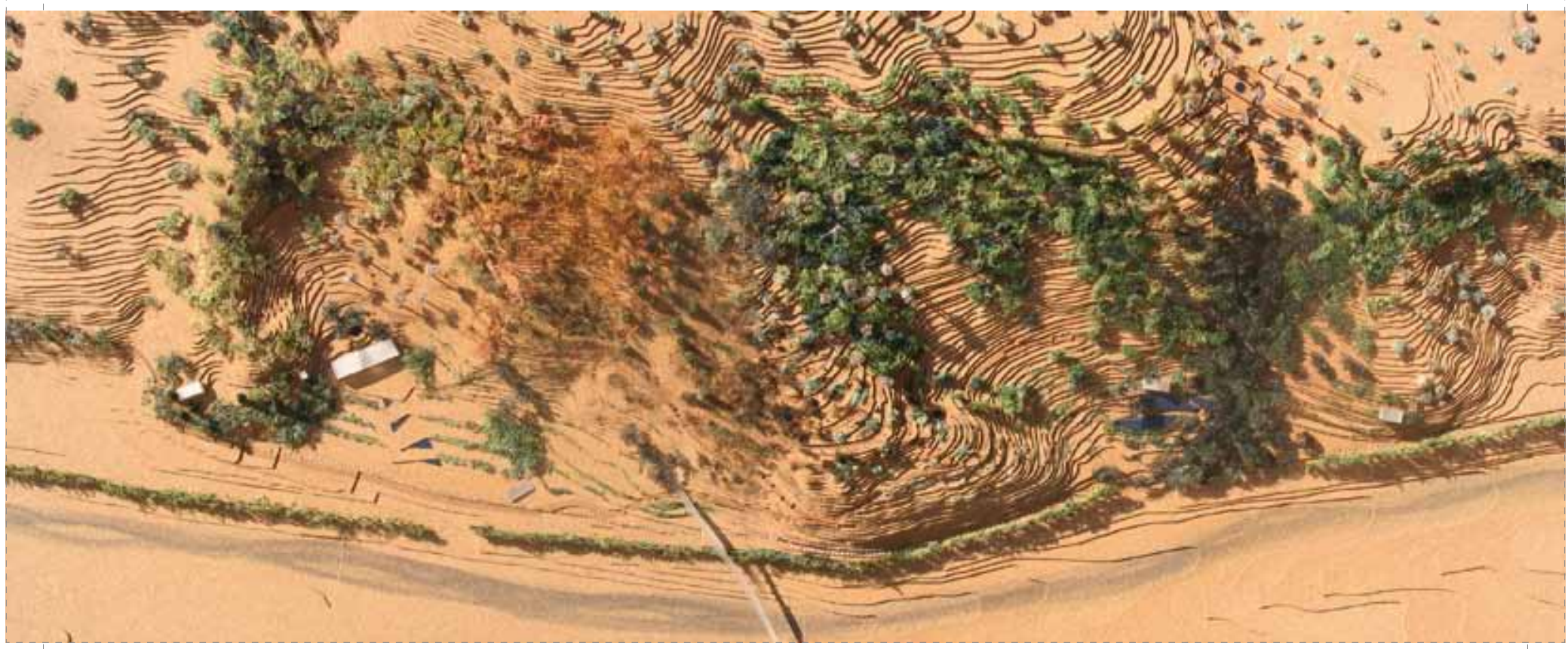

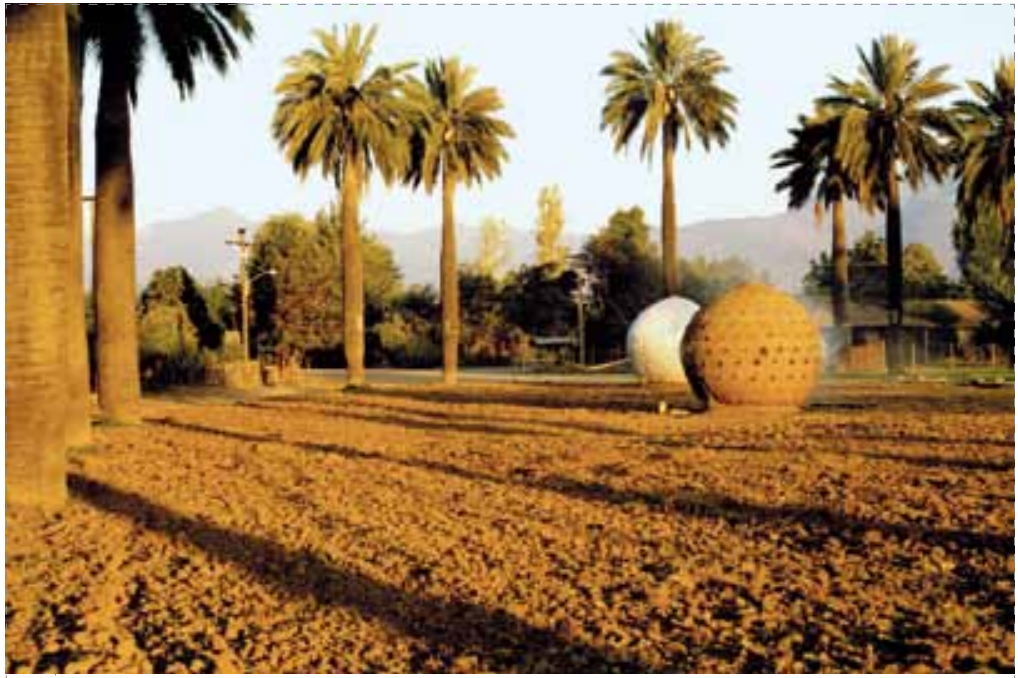

Imagen 16. Campo Püblico en Culiprán. Smiljan Radic (fuente: Smiljan Radic).

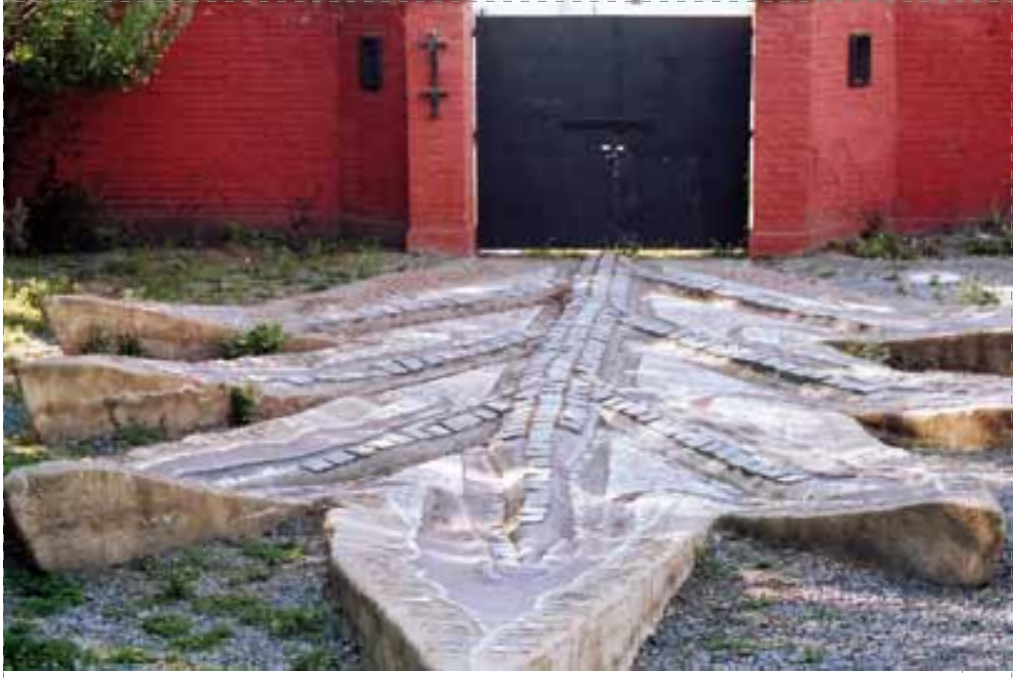

Imagen 17. Parque Por la Paz. Torrealba, Felsenhardt, Gajardo, Santibáñez y Ramírez (fuente: Fulvio Rossetti). de la memoria. Si los primeros experimentos "fundativos» de esta actitud se pueden encontrar en las primeras obras de Carlos Martner por la voluntad de expresar a través de la obra la cultura del pueblo, también las experiencias de fin del ' 80 marcaron su huella por lo que concierne al territorio.

Obras como el Campo Público en Culiprán (Smiljan Radic) (Imagen 16), el Parque Por la Paz (Torrealba, Felsenhardt, Gajardo, Santibáñez, Ramírez) (Imagen
17), el Patio de la Facultad de Biologia UC (Cristina Felsenhardt) (Imagen 18), el Parque Bicentenario de Vitacura (Imagen 19) (Teodoro Fernández), la Plaza de la Ciudadanía (Imagen 20) y el Parque del Portal Bicentenario (Myiriam Beach, Pía Montealegre) (Imagen 21) se han concebidos a la luz del recuerdo de eventos históricos u objetos relacionados a la memoria colectiva: las carboneras del paisaje costero en el Campo Público, los recuerdos de los detenidos en el campo de tortura del ex cuartel Terranova en el
Parque por La Paz, las acequias de los patios antiguos de Santiago en el Patio de Biología UC, los Tajamares del Mapocho en el Parque Bicentenario de Vitacura, el acto simbólico de abrir las cortes de La moneda en la Plaza de la Ciudadanía, la pista de aterrizaje del ex aeropuerto de Cerrillos en el Parque del Portal Bicentenario. Significativo es también el proyecto aún no realizado del Parque La Aguada Oriente, (Masterplan: Pablo Allard y José Rojas, Proyecto definitivo: Juana Zunino y Mitzi Rojas) (Imágenes 22 y 23) que, junto 


\section{$\begin{array}{llll}\text { N } & 0 & 1 & 9\end{array}$}

de arquitectura

Imagen 18. Patio Biología UC. Cristina Felsenhardt

(fuente: Fulvio Rossetti).

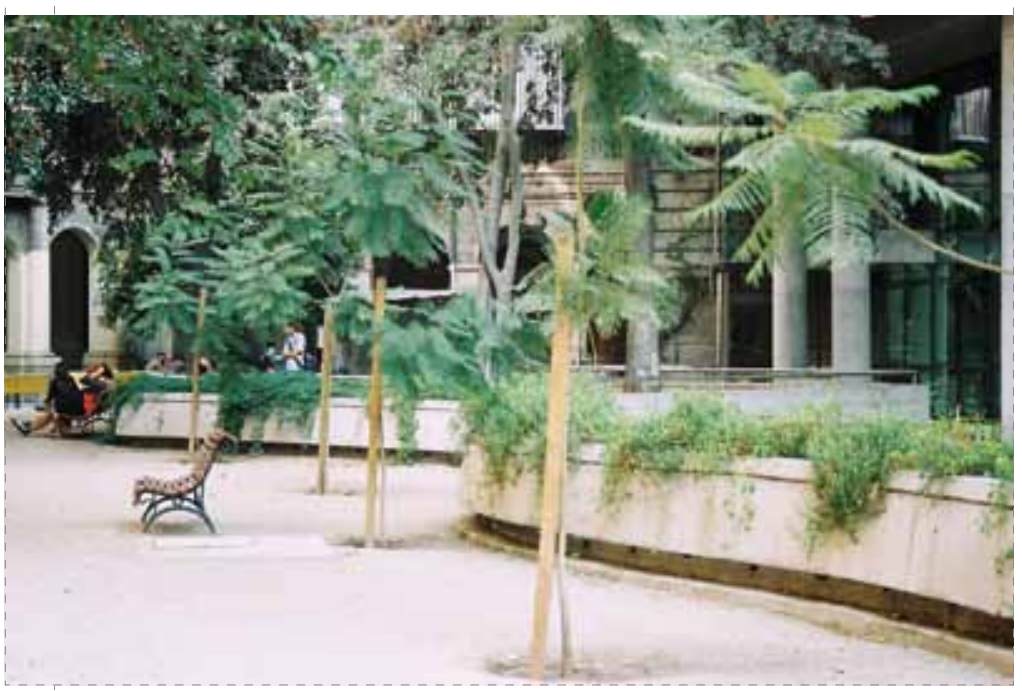

Imagen 19. Parque Bicentenario, vista del paseo superior Teodoro Fernández (fuente: Fulvio Rossetti).

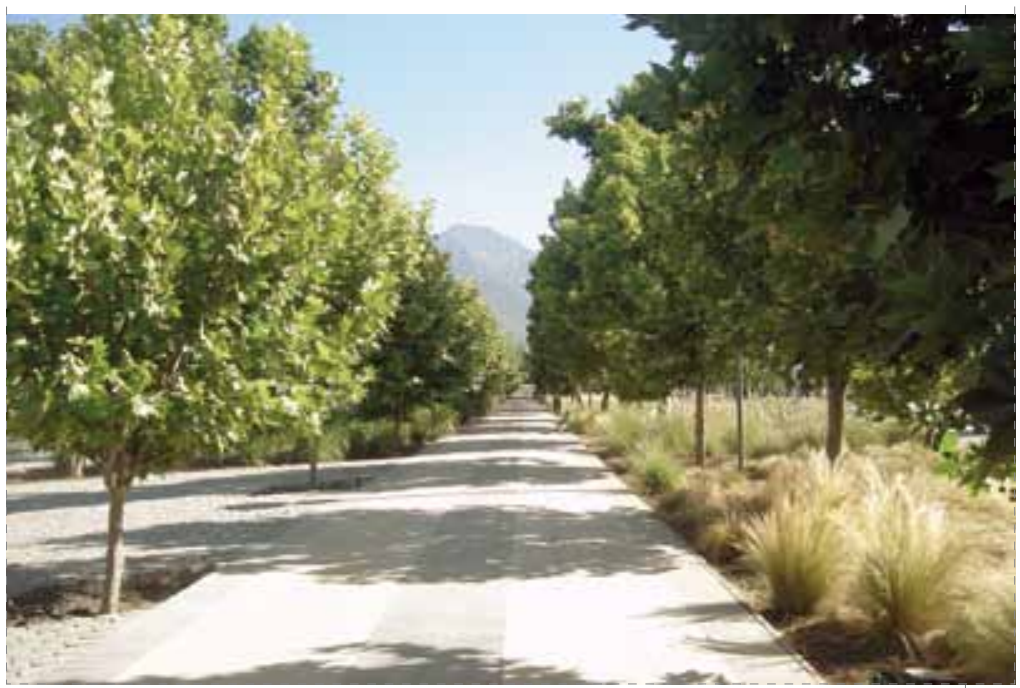

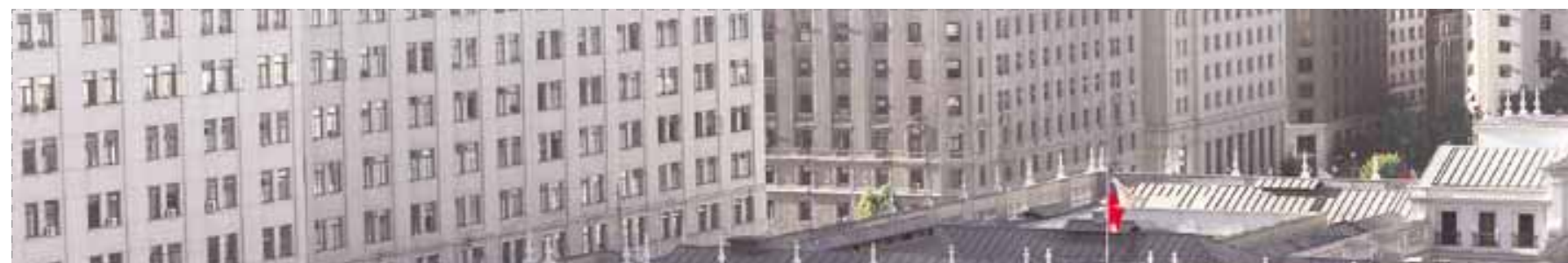

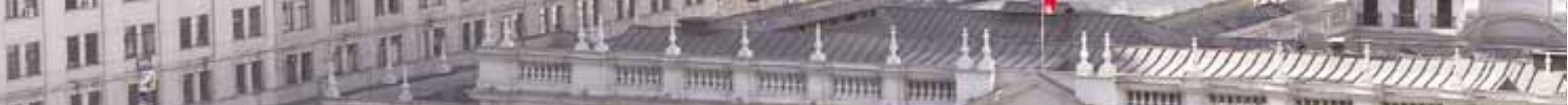

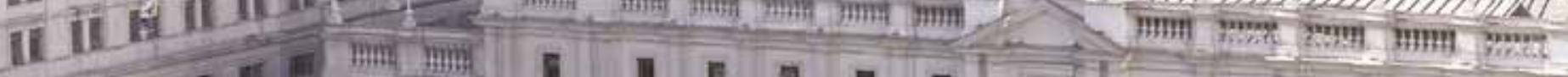

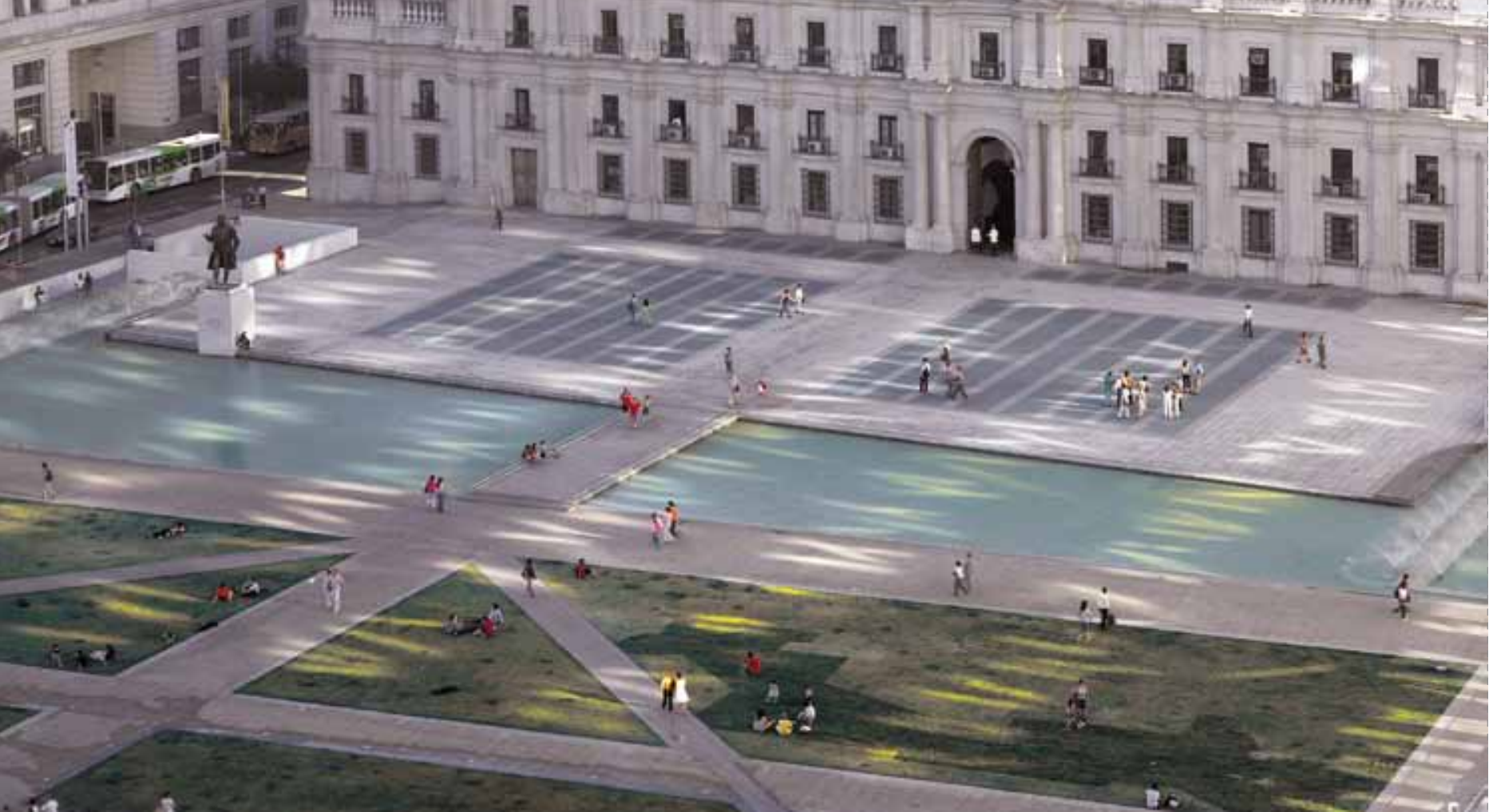

Imagen 20. Plaza de la Ciudadanía. Cristián Undurraga (fuente: Guy Wenborne). 
Imagen 21. Рагque

del Portal Bicentenario. Myriam Beach y Pía

Montealegre (fuente:

MB arquitectos).

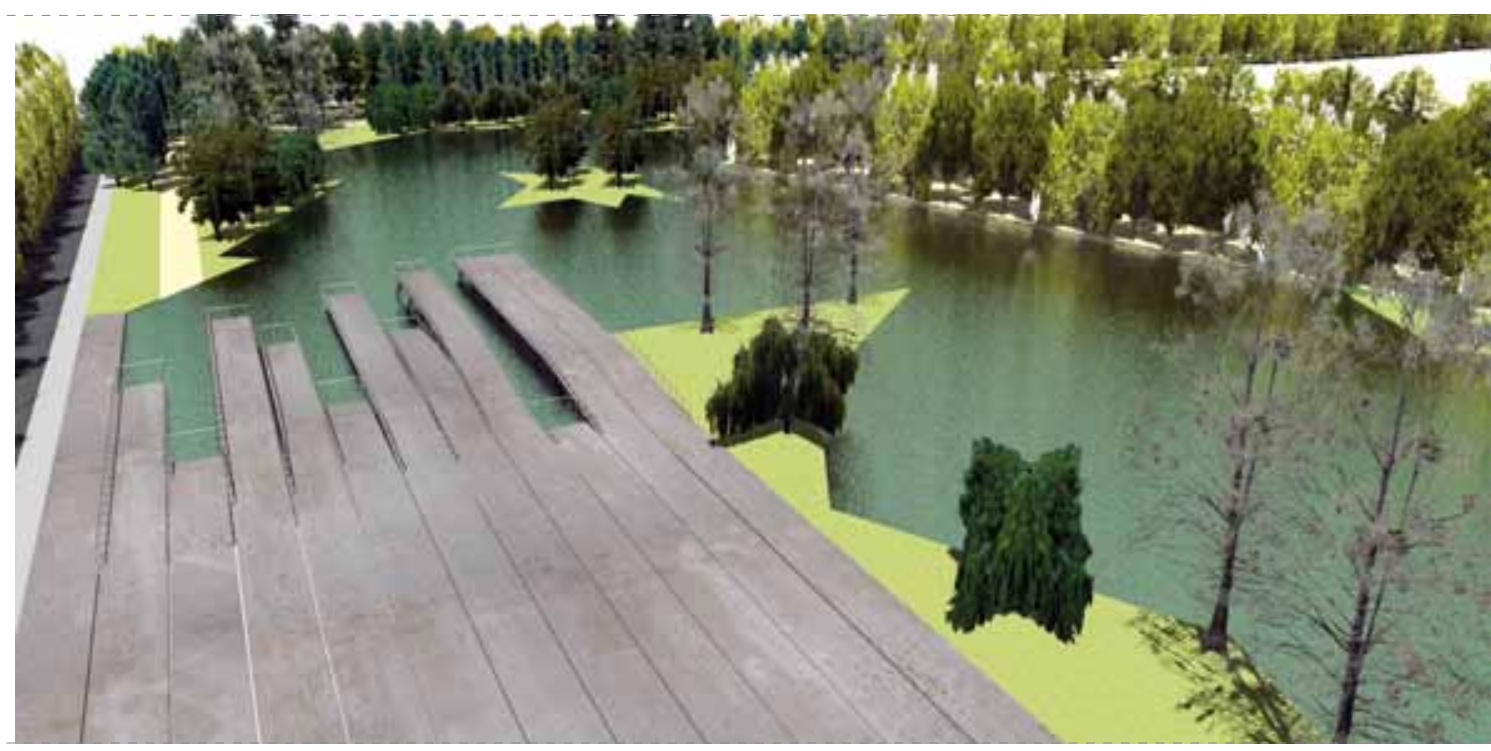

Imagen 22

Anillo Metropol itano. AAVV (fuente: MINVU).

Imagen 23. Рarque La Aguada Oriente sistema hidráulico entre lagunas. Allard, Rosas. Zunino y Rojas (fuente Claudia Echevarría).
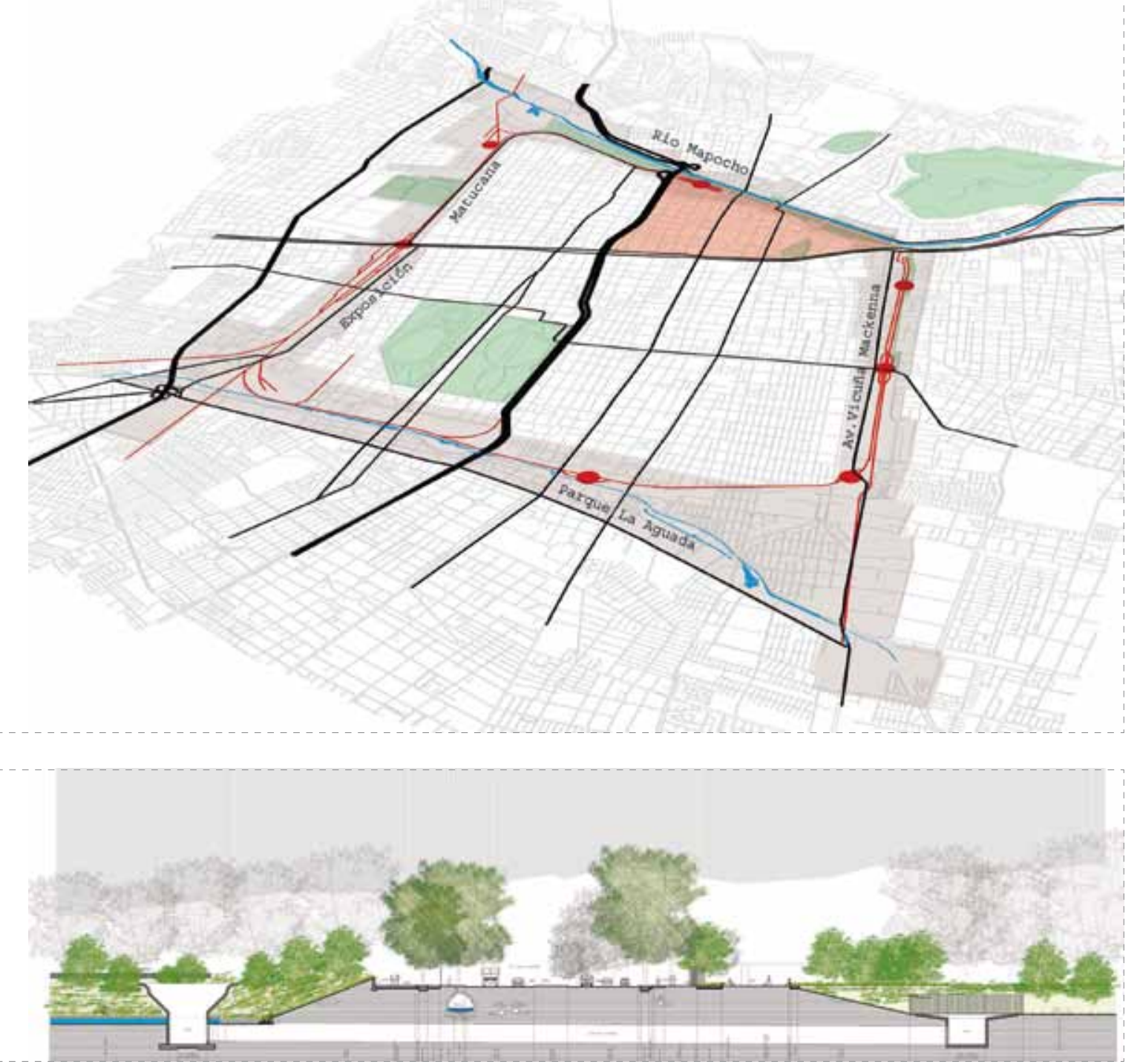
Imagen 24. Termas Geométricas. Germán del Sol (fuente: Guy Wenborne).

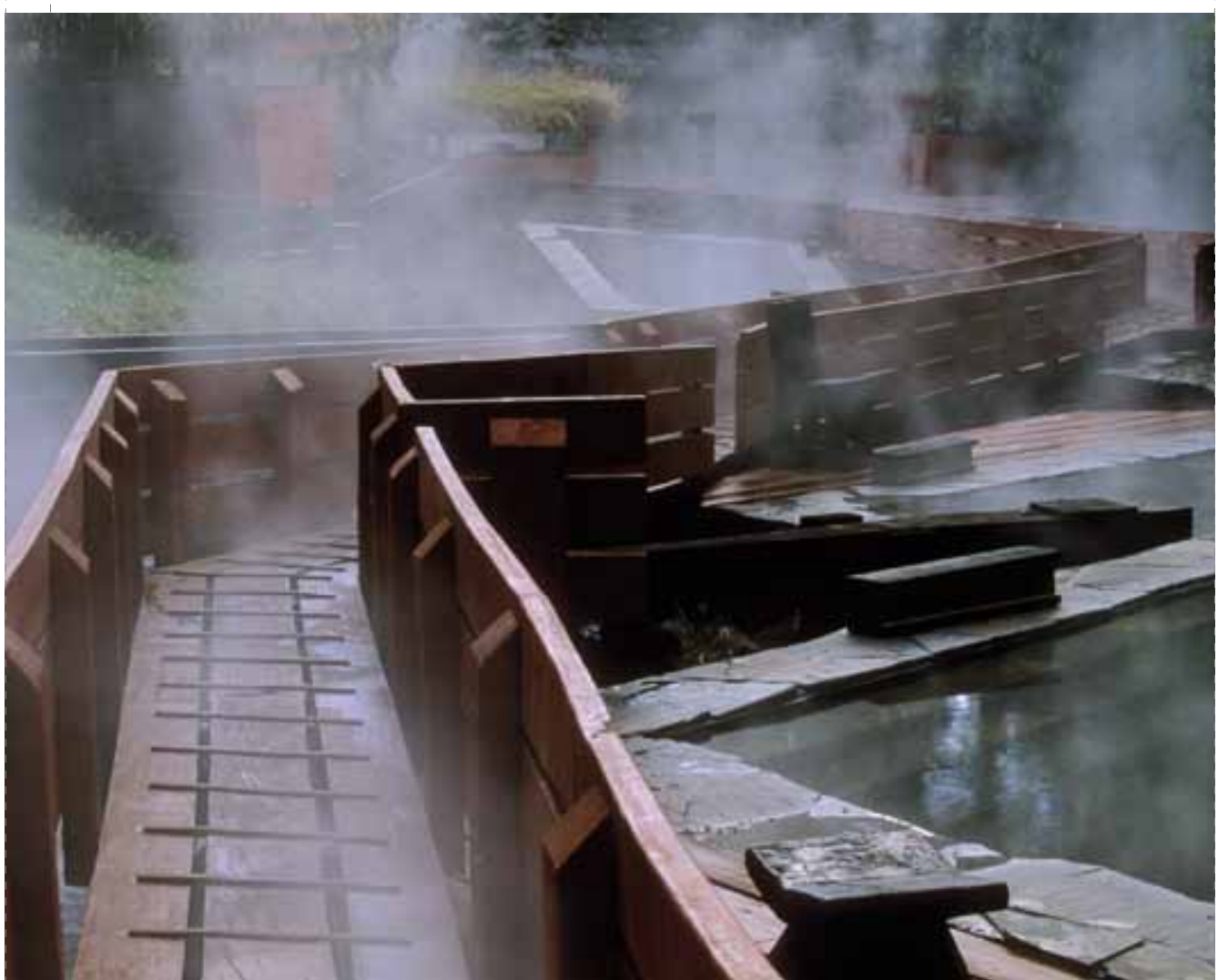

con el proyecto del anillo metropolitano del que forma parte sustancial, cierra un ciclo histórico: al cumplirse el segundo Centenario de la República (2010), el anillo verde consolidaría la huella dejada por Vicuña Mackenna más de un siglo antes con su camino de circunvalación.

En fin, una actitud poética, es decir, una manera «meditativa» de concebir el proyecto en el paisaje que consiste en comprender el significado de un lugar y en ese integrar «signos»: señales de vida humana que apuntan a poner en escena algún aspecto específico de la naturaleza del sitio. De alguna manera se pueden entender las experiencias de este tipo como proyectos en que la sustentabilidad, concebida bajo el punto de vista subjetivo del autor, adquiere valores conceptuales y formales: Inquietud primordial es entender los fenómenos del paisaje, para reinterpretarlos en las formas visibles de proyecto. La geometría abstracta: arquetipos, signos y grafismos, genera un «interior antrópico, al mismo tiempo de hacer patente e significado del paisaje original. De esta forma, desde las similitudes con el entorno, la obra genera una ambigüedad en que cuesta definir qué es natural y qué no.

Las Termas Geométricas y las Termas de Puritma (Germán del Sol) (Imágenes 24 y 25) la Rambla Punta Pite (José Domingo Peñafiel y Teresa Möller) (Imagen 26) los Miradores de los Embalses Santa Juana y Puclaro (Carlos Martner) (Imágenes 27 y 28) son ejemplos emblemáticos, tal vez los únicos rescatables de esta manera de entender el proyecto de paisaje.

\section{Conclusión}

Llegar a una conclusión sobre un proceso que está lejos de concluir, o mejor recién está empezando, es tarea complicada.

La búsqueda de alguna tendencia en un quehacer artístico, algo como «grupos de pensamiento», seguramente difícil en tiempos de globalización, puede convertirse en una "caza de brujas» en un continente como el sudamericano, donde en general no existen políticas estables ni recursos tan abundantes para hacer que las aproximaciones al paisaje de algunos se puedan convertir en estímulos para difundir una cultura medioambiental generalizada. Más bien, como subraya Jimena Martignoni en Latinscapes, el paisaje como materia prima, las experiencias destacables son el fruto de la genialidad y perseverancia de algunos hombres que han sabido desarrollar

Imagen 25. Termas de Puritama. Germán del Sol (fuente: Guy Wenborne).
Imagen 26. Rambla Punta Pite. José Peñafie yeresa Möller (fuente: Fulvio Rossetti). 


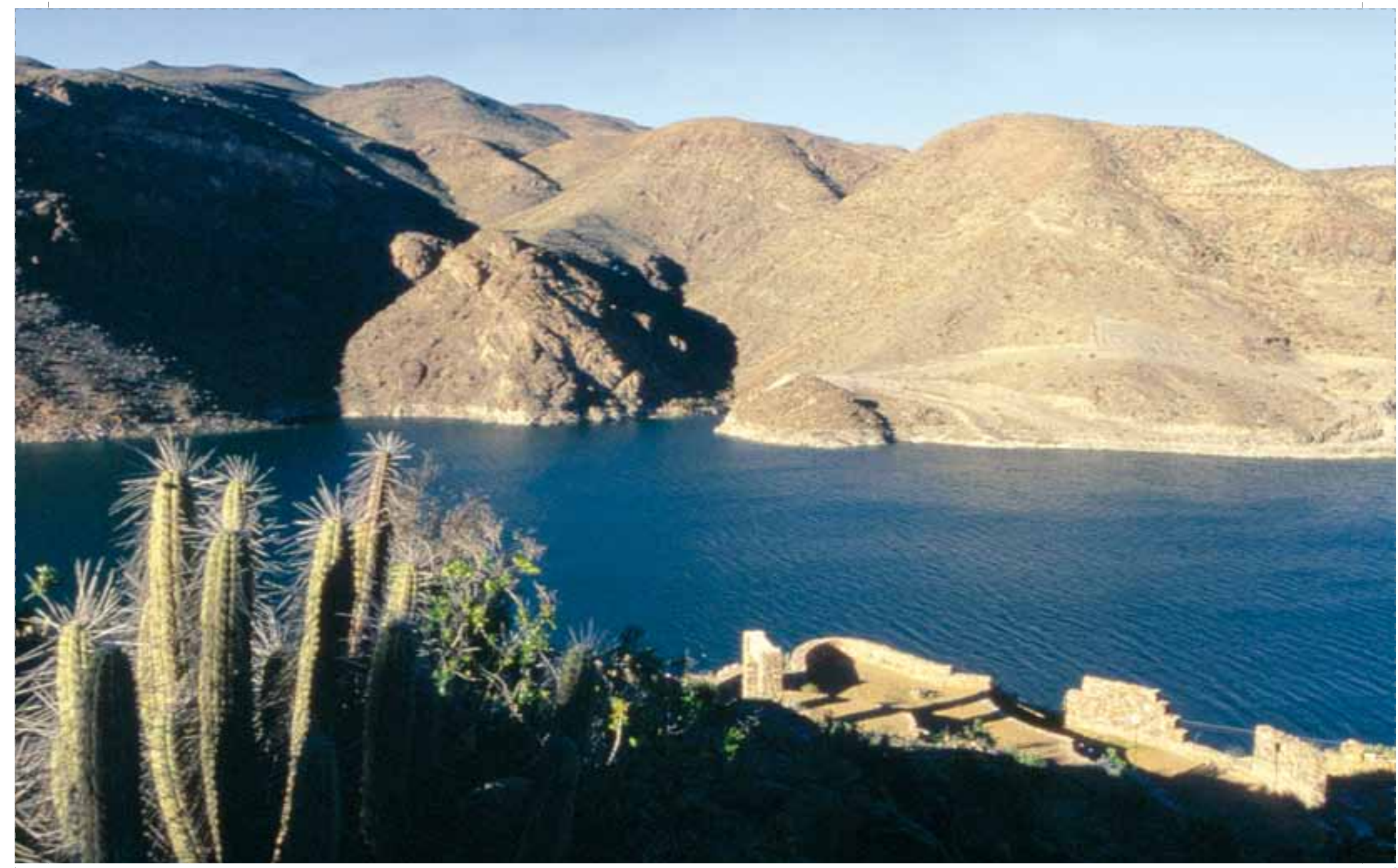

Imagen 27. Mirador del Embalse Santa Juana. Carlos Martner (fuente: Guy Wenborne)

Sin embargo, si en el Chile actual la situación antes descrita es un hecho, también es posible encontrar las semillas de un cambio de paradigma; semillas que probablemente deben su razón de existencia a la diversidad políticoeconómica que ha construido el país en cuanto a estabilidad y presencia de recursos.

Chile está viviendo un momento singular debido a la contemporaneidad de algunos hechos: bajo el punto de vista político vive el período de «transición a la democracia», que sigue a la dictadura pinochetista, y desde el final de los '80 se ha mantenido constantemente bajo coaliciones de gobierno centro-izquierdistas; económicamente se encuentra en un lugar privilegiado del escenario geo-politico continental e históricamente está cerca de cumplir doscientos años de república (2010).
Así los nuevos paisajes, posibles no solamente por la disponibilidad de recursos de que no se disponía anteriormente, se están definiendo, por un lado, como resultados de estrategias para el bienestar y la salud pública -no es un caso que varios de los proyectos expuestos en este artículo son iniciativas gubernamentales, fomentadas por organismos locales y nacionales-y por otro como manifestación de la voluntad de afirmación nacional e ideologías políticas.

Si encontrar una tendencia formal en estos proyectos es difícil, si se puede entrever un afán general por generar algo nuevo y distinguirse en el plano internacional, lo que se puede sintetizar en voluntad de identificación, tanto más comprensible si se observa que en la historia del país el período analizado corresponde a la primera vez en que éste -a diferencia de otros países sudamericanos- entra a las vías del desarrollo. Sin embargo un proceso de «identificación» no puede definirse sin relacionarse con las raíces culturales de un pueblo, así que a menudo los nuevos proyectos han tratado de recuperar, en una nueva clave de lectura, tradiciones urbanas ya fundamentadas antes de los años ' 70 como es el caso del Parque Bicentenario, con su proceso de abstracción sobre los tajamares del río Mapocho y el intento de una síntesis entre el naturalismo de Óscar Prager y la influencia francesa del Parque Forestal de Santiago. Proyectos como el mirador del embalse Santa Juana, la Rambla Punta

Pite, las Termas Geométricas y el campo público en Culiprán intervienen sus sitios geográficos reinterpretando elementos del imaginario colectivo y logrando un sentido de «atemporalidad» que permite la apropiación cultural del paisaje. Por otro lado la afirmación de una identidad nacional y el mejoramiento 


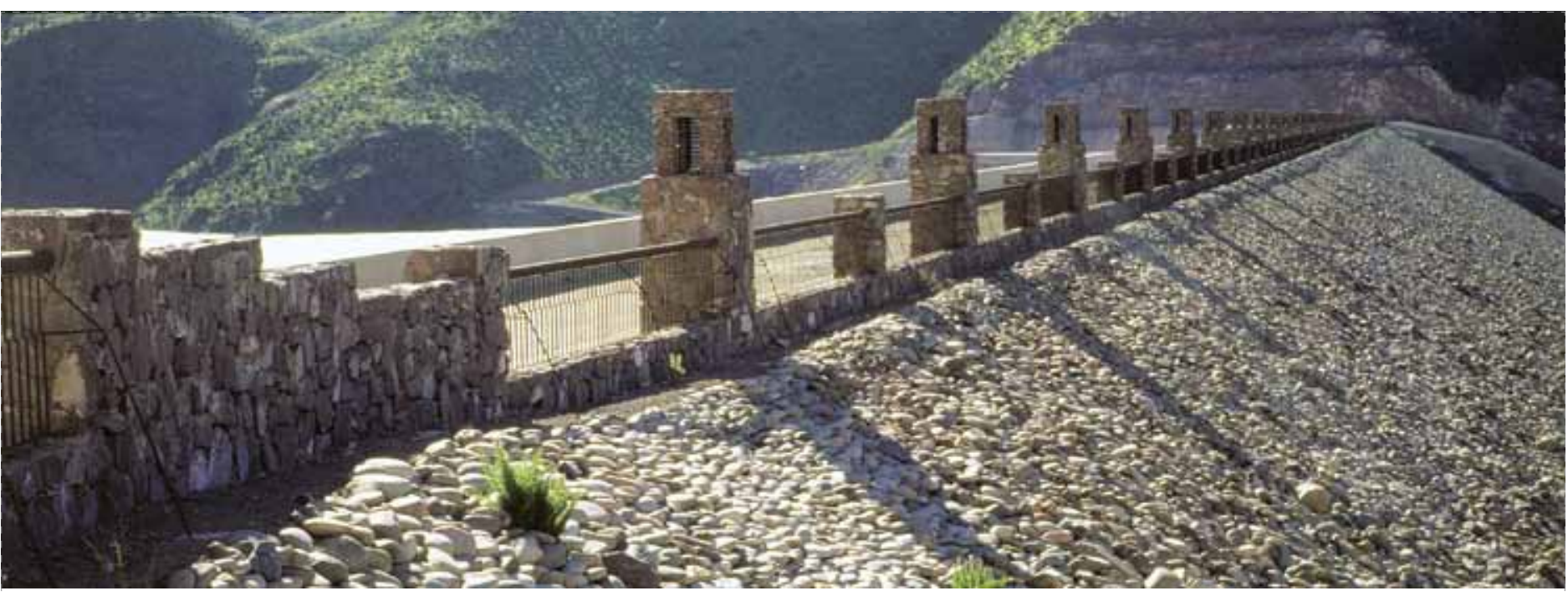

Imagen 28. Mirador del Embalse Puclaro. Carlos Martner (fuente: Guy Wenborne).

En la fotografía de la página derecha, una vista desde el Mirador del Embalse Puclaro (fuente: Salvador Verdejo).

de una imagen país desastrosa por su historia reciente son evidentes en una obra como la Plaza de la Ciudadanía.

Si la principal característica de la globalización es la extrema especialización y división de os roles productivos, asimismo, el medio ambiente actual, especialmente en un mundo tan dinámico como Chile, con su rápido desarrollo, corre el riesgo de resultar afectado por una producción que no negocia con una necesidad tan básica como el ambiente a medida humana. Si ya el fracaso de la ciudad de los números, de los años '60, ha demostrado lo utópico de la planificación urbana en base a cálculos matemáticos, al día de hoy se hace preocupante la disociación existente entre los distintos actores que intervienen sobre el ambiente. Preocupante es ver que existe un mundo de las infraestructuras, que entreteje sus redes haciendo tabla rasa de las necesidades locales; un mundo de la vivienda, que responde a la demanda habitacional pero no se preocupa de ningún criterio urbanístico; un mundo del libre mercado y otro gubernamenta que parece más débil y no siempre logra seguir el paso de la expansión urbana; y el mundo del antejardín y del arbolado urbano con que, a veces de manera grotesca, se trata de poner un parche a la desintegración del medio ambiente; proyectos como el Parque Botánico el Chagual, el Paisajismo para la Reserva y los Corredores ecológicos Viña Emiliana, muestran una naciente preocupación para el medio ambiente. Frente a la fragilidad de este último, la transversalidad de la disciplina paisajista se presenta no como un concepto abstracto o académico, sino como una emergencia real. De esta forma, la medida humana, independiente de que se busque en la belleza natural, en el sentido de identidad y pertenencia, o en la interpretación artística de la naturaleza, no puede verificarse si la manera clásica de concebir el paisaje no negocia con las condiciones reales del mundo actual.

Encaminado hacia un quehacer contemporáneo, el desarrollo de la Arquitectura del Paisaje de Chile se encuentra en un momento importante, en una fase de transición donde la negociación antes mencionada, tendiente a un proceso identificativo, resulta por lo menos declarada, como una buena promesa para el futuro.

\section{Bibliografía}

- Isabel Fuentes, Liliana Lanata, Eduardo Vilches, Marta Viveros. Óscar Prager: El arte del paisaje. Santiago, Chile: Editorial ARQ, 1997.

- Daniel Swinburn del Río. «Óscar Prager: El arte del paisaje». En: ARQ (artículo de revista) 1998; 39: pp. 69-70.

- Geoffrey Alan Jellicoe. El paisaje del hombre la conformación del entorno desde la prehistoria hasta nuestros días. Barcelona: Editorial Gustavo Gili, 1995.

- Humberto Eliash, Miguel Laborde. Carlos Martner: Arquitectura y paisaje. Santiago,
Chile: Editorial Facultad de Arquitectura y Urbanismo, Universidad de Chile. 2003.

- Carlos Martner. «El Cerro San Cristóbal en el paisaje de la ciudad: Obras entre 1960 y 1975». En: ARQ (artículo de revista) 1996. 34: pp. 4-7

- Stuart Wrede, William Howard Adams. Denatured visions: Landscape and culture in the twentieth century. Nueva York: Editorial MoMA, Museum of Modern Art, 1991.

- Horacio Torrent. Arquitectura reciente en Chile: Las lógicas del proyecto. Santiago, Chile: Editorial ARQ, 2000

- Teodoro Fernández. «Viñas y corredores ecológicos». En: ARQ (artículo de revista) 2003; 54: pp. 52-55.

- Teodoro Fernández. Parque Las Américas (Memoria proyecto). Santiago de Chile, 2003. Documento inédito.

- Teodoro Fernández. «Paisajismo para la Reserva». En: ARQ (artículo de revista) 2004; 57: pp. 46-49.

- Ricardo Astaburuaga. «El agua canalizada», "La casa huerto» y «La cuadrícula». En: Morfología de Chile y sus ciudades. Santiago, Chile: Ril Editores, 2002; pp. 54, 57 y 94

- Rodrigo Pérez de Arce. «Santiago de Chile, el paisaje y la invención del país». En: Paisagens culturais, contrastes sulamericanos. Rio de Janeiro: Maia Editora, 2008; pp. 109-119.

- Jimena Martignoni. Latinscapes, el paisaje como materia prima. Barcelona: Editorial Gustavo Gili, 2007. 
